\title{
Developing Innovative and Interactive Learning in Elementary School
}

\author{
Alif Mudiono \\ Elementary School Teacher Education \\ Universitas Negeri Malang \\ Malang, Indonesia \\ alif.mudiono.fip@um.ac.id
}

\begin{abstract}
Teacher is an education personnel who has humanity responsibility, particularly it is concerned with learning toward the next generation of the nation toward innovative and interactive learning. The biggest responsibility expected is the teacher owns high professional competence, the teacher can create an innovative and interactive learning strategy in order to ease the delivery of their learning process which is easily understandable for the students. In this paper, several points explained are (1) constructivism as based on innovative and interactive learning, (2) teacher's challenging and expectation to face the development of innovative and interactive learning, (3) teachers expectation to develop innovative and interactive learning, and (4) principles of developing innovative and interactive learning.
\end{abstract}

Keywords - learning, innovative, interactive, elementary school

\section{INTRODUCTION}

Innovative and interactive learning meant as learning which designed by the teacher that in new characteristic, it did not do in ordinary habit, and purposed to support the student in developing knowledge of themselves in the processing of behavior changing to the better direction who appropriate with their potential and differences of the student. This case, similar statement with Suciati that innovative and interactive is as implement ideas, processes or tool to achieve the best performance [1]. Innovative and interactive learning is a learning process that designed so that it's different from general learning that implemented by the teacher (conventional). These differences direct to the better process and result from the past. Learning process all this time implemented inclined to aim to memorize concept and theory in abstract characteristic.

Learning all this time occurred was learning that meant as conventional learning, it was only focused on verbal communication, teacher-centered, and authoritative learning, it meant the teacher had authority to determine the lesson that student learn and conception that did not provide space of creativity for student although the teacher in developing innovative and interactive learning. It made the student less of interested and motivated in attending learning activities that have low learning result and knowledge has not meant that got by them. Besides, the lesson learned by the student through separated from the daily life problems that faced by students. Paradigm (conviction) instructor on that time mentioned behaviorism that behaviorism has characteristics: (1) knowledge is an object that characterized definite and precise, (2) study is directed as achievement knowledge, (3) teaching is transferring knowledge to the student, (4) students is expected own the same knowledge with teacher for material that learned, (5) the purpose of learning is emphasized to add the knowledge, (6) learning is emphasized to study result, not in the study process. Learning-oriented in behaviorism is more emphasized study result that implemented in all kind way than study process [2].

The relevancy of the paradigm above Gasong clarified behaviorism, a study of changing behavior as the result from the interaction between stimulus and response [3]. The changing has been experienced by the student in their ability to behave using a new method, that is the produced during stimulus and response. Practical of behaviorism met in learning by using lecture learning method or often called direct learning method and drilling. Learning using pure lecture method was going to become a teacher as one of study source whereas the student only accepted the material from the teacher.

\section{CONSTRUCTIVISM AS BASE OF INNOVATIVE AND INTERACTIVE LEARNING IN ELEMENTARY SCHOOL}

In 21 century almost all of the teaching material had available in digital form. We have known terminologies of ebook, e-journal, digital media and, soon. This case indicates that the sources of studies used in the school can be accessed or got the student through the internet. Laptop owned by the student can be filled with the source of study so that they do not need to bring a big bag and a lot of books to the school. Internet access in the school or certain place is more easy and cheap. The most effective way of involving the student is developing active learning in which the learning can involve the student in their learning activity. That involving includes the cognitive activity, effective, and psychomotor.

In other condition, we as the teacher is not ready well to teach in technology-based. The learning activity is still more accepting information compared to build the concept through the though activity. Therefore, we as the teacher in 21 century face the various challenging, Arend dividing in seven teaching challenging, as follows [4].

First, teaching is an active learning. Active learning was often not implemented by the teacher because it formed the opinion of the teachers that implementing active learning spends a lot of time [5]. In implementing active learning, the strategy is involving the student in some activities by doing a learning activity and thinking about what they have done. This strategy can involve the student in achieving the purpose of study about (1) through critical and creative, (2) discussed in a small group or between classmates, (3) presenting the ideas through the article, (4) developing the attitude and norms that owned the student, (5) presenting and 
accepting the suggestion of their friends, and (6) implementing of reflection toward learning process which have done or about understanding material that has learned also.

Second, teaching a multicultural subject. Multicultural in the classroom cannot be avoided in the school learning at this time. Together with fast globalization so the student from a school can come from other tribes, religion, or race. These conditions have to able to become the power of the learning process so that students can learn with their friends.

Third, teaching is for construction or comprehension. Comprehending the student for constructing concept needs active activity so that occurred though activity. The students must be motivated to think what they are doing and what the purpose of that activity. The active learning strategy is students centered learning or based constructivism learning to teach the student to construct the concept.

Fourth, learning and technology. Teaching in 21 century have to get utilizing technology in the learning activity. Not only based computer technology but also all technology can make the student easy to learn and improve the competence of critical thought, creativity, and facilitation of comprehension access.

Fifth, teaching and responsibility. Developing science and technology cause many interesting technology products and have variation especially for doing hobby and fun. For simple example are television and mobile phone. Almost all the students have a television at their home so they can watch or play a game after school. Many students spend their time to watch TV and play a game. If the student was not taught in responsibility so they would forget the homework which provided by the teacher from their school because watching television was interesting. On that account, the teacher in 21 century has to get to bring the sense of students toward the responsibility.

Sixth, teaching in selection class, learning in 21 century directs to particularity (specification). Development of innovative learning can direct the learning in the special matter. Therefore, the teacher has to get to implement innovative learning in selection class. In certain unit education level has a specification and selection. For example, selection of natural science field, computer class selection, language and literature, and social science selection. The existence of the selection class demands the teachers to improve the learning comprehensively and deeply. Learning in elementary school and junior high school determined as cohesive learning. This learning model is also selection class because the teacher has to prepare the learning purposely which the character of the subject is not visible but it is to be unity.

Seventh, teaching with new interpretation about the competence. Teaching with the interpretation that the student competence is not only cognitive skill but also it is covered skills or competencies related the other intelligent such as musical intelligence, special intelligent, and emotionally intelligent. Developing emotional intelligent in learning became a challenge that is more important in this 21-century learning.

\section{THE EXPECTATION OF TEACHER IN DEVELOPING INNOVATIVE AND INTERACTIVE LEARNING IN 21 CENTURY}

The teacher expected to give attention or direct the learning based on seven things which become teaching challenging in 21 century [6]. The challenges can direct the teacher to develop innovative and interactive learning based on constructivism or student-centered learning. For developing innovative and interactive learning, a teacher needs to comprehend developing principles of innovative and interactive learning.

Innovative learning is not always implementing new learning method, but it is more changing that occurred in conventional learning to active and interactive learning. Active learning, it is meant learning that can involve the student and between the student and with the teacher. Direct learning changing or conventional learning is the teachercentered to students centered learning indicates of the main indicator occurred in innovative learning [7].

\section{DEVEloping PRINCIPLE OF INNOVATIVE, INTERACTIVE AND CREATIVE LEARNING}

To develop innovative, interactive, and creative learning, Kauchak and Eggen clarify that the student expected to notice the principles of learning, as follows [8]. First, learning must be designed appropriately to grow intellectual, emotional, social, physical potential, art, and creative part of the student. Intellectual growth will be able to optimize if they invited for thinking not to memorize the material. These characters are more important observed in developing learning in order to learning process has balancing with student cognitive level. The cognitive level that purposed is though level, emotional level, and other condition levels.

Second, learning has to involve the student in the learning process and motivate personal responsibility and collective actively. Involving the student actively through the activities cause of interaction occurred; it will be able to develop a social attitude and the other social competence. The teacher can choose the strategies or models of learning that can involve the student. Generally, student-centered learning will involve the student to study.

Third, learning process indicates to search comprehension and meaning which arranged by interaction activity between the student or the other student and teacher. The learning process is a concept of constructing activity not only accepting the information. The student motivated to comprehend the material that has learned not memorizing the material.

Fourth, learning has to able to take care of the healthy children, intact, own high curiosity that can study whatever they want to know in a new context. Generally, productive and creative students have to get accommodation in the learning process. In this case, needed art classroom management where the student has progression study motivated by the teacher to guide their friends. Creating a heterogeneous group discussion can help this condition.

Fifth, learning must be able to comprehend the student to accept and understand the context that creates and provide the meaning for life using the introduction method to the student concerning the planet entirely, the life of earth, and development of world society. This statement directs to local 
learning that exist around the school or environment of the student.

Sixth, the teacher confesses innate potential in every student to be smart, creative, and systematic thought. In innovative and interactive learning the result of the student work must be appreciated. Some of the schools display the students work on the school wall. This condition is a very positive situation for the student where they are confident to look at their work closely with their friend's work. The potential of students can be given facilities by the teacher so that they can be developed.

Seventh, learning can motivate the student to close the culture, morality, and political context in their life critically. Besides, mastery of material (theory, law, principle, and concept) in innovative learning, the student lectured about culture, good morality (polite attitude and good character). Developing of Innovative learning has to able to grow on the culture not only developing thought competence. Learning activities do not opposite with the culture, morality, or higher values of Indonesia notion.

Eight, learning must respect of higher values and spiritual knowledge. The spiritual has the connection in our life, respect of diversity in unity. Innovative learning developed in the classroom cannot disfigure or offend religion values in Indonesia society. Innovative learning must respect and accommodate the diversity of student in classroom or school.

Ninth, the learning process can make the student own overawe and respect toward universe mystery and purposed sense in life. In the last learning, the student can reflect or contemplate that what exists in nature, what the student own and enjoy their life is our gift from the God.

\section{DEVELOPING INNOVATIVE AND INTERACTIVE LEARNING PROCEDURE}

Developing innovative and interactive learning procedure can follow ten steps as follows. First, basic competence analysis and development learning indicator. Identification standard competence and basic competence from the material will be taught. By this basic competence analysis, we will know the material that we want to teach. From this material expand the map concept material completely. The sequence to down from map concept indicates a sequence of material presented. Whereas spread of material to the side is indicated of spaciousness material. Based on map concept, expand the learning indicators. The indicator has formulated "operational verb" continued the material or concept in the map concept.

Second, the material analysis is for achieving competence. This analysis is meant for knowing the sequence, spaciousness, and depth of material that must be taught to the student in a certain time [9]. From map concept in a step before we have known concepts that will be taught. The mentioned concepts have identified the sorts whether concrete, abstract, procedural, or metacognitive. If concrete concept so relevant strategy is a direct observation or the real object activity like an experiment. If it is abstract, it is needed learning strategy that can guide the construction concept as a learning cycle, inquiry, or learning based on the problem.

Third, student's characteristic analysis (they can do work autonomous, group, and, so on) [9]. Student characteristic is very essential to be considered in determining a learning strategy for designing innovative learning. Besides, consideration of thought level, the rapid learning level of the student must be considered. If the rapid learning level of student is low, so providing an example and analogy needs to give to the student massively. On the other way, if the rapid learning level is high, so the examples give a few to the student but a problem-solving question gives more question to the student.

Fourth, determining of presentation strategy (learning method). Strategy or learning model has chosen which must be appropriate or suitable with the characteristic of the material and the student characteristic. In innovative learning, constructivism learning approach or studentcentered learning become the first choice. So that, the strategy has chosen, it is oriented constructivism strategy or model.

Fifth, learning resource analysis (learning resource integration besides textbook) the next activity is gathering relevant learning resource with material that will be taught. After knowing the material and strategy that we are used, choose the relevant learning source with considering: relevance with curriculum, contextual, sequences of material, depth and width suitably, it does not contain misconception, and interesting for the student. In innovative learning, generally, texts of learning resource will be closed with learning media that obtained from the Internet such as video, audio, picture, and etc.

Sixth, developing a lesson plan. After the previous five stages that we design. Next, we will foster of implementing the lesson plan. The most important part of a lesson plan is "learning steps" consist of beginning activity, core activity, and closing. In the opening activity, we have to get a connection of beginning knowledge of student about what they have learned and what they will be learned in meeting planned. In core activity, lesson plan has followed by approaching steps, model or method that we chose. Whereas, in closing activity, we must teach the student doing reflection about what they are learned and connected or contemplated of material that they are learned by the almighty of God, values, and good norms for their life.

Seventh, implementing innovative and interactive learning. Implementing innovative learning in the classroom will be easy than direct learning. Learning will implement well because it has made detail planning. In the implementing stages, it is very important to be noticed in time management and classroom management.

Eight, assessment has done by teacher covered assessment process; the teacher can do the assessment toward the student activity as being active, quality of discussion result, manner, and skill that planned in the lesson plan.

Ninth, assessment has done by teacher covered assessment process and assessment after learning. Generally, assessment after learning has worked well because it is using the prepared test. Whereas, during the process, the teacher has to implement of assessment toward the student activities as being active, quality of discussion, manner, and skills that have planned in the lesson plan.

Tenth, developing principle of innovative learning that what the students learned have to get increasing of believing 
in the God, so the last of learning has to be implemented of reflection about what the student learned. That reflection has to get providing contemplation of the student and always to thanks a God. Besides, the teacher has to do the reflection toward the lesson plan and implement the learning that was done.

\section{INTEGRATED MODELS IN LEARNING}

Fogarty states that found ten curricula integrated models in learning [10]. Ten models are famous with an integrated curriculum. Each model explained are fragmented, connected, nested, sequenced, shared, webbed, treated, integrated, immersed, and networked model.

\section{A. Fragmented Model}

Fragmented model is a separate model that is looking curriculum in cutting the subject that separated. The fragmented approach implemented by combining concepts and competence in a subject between competences learned.

\section{B. Connected Model}

This model focused on making an explicit connection in every subject. Connecting a topic to the other topic, connecting a concept to the other concept, connecting skill for concerned skill, connecting work a next day or ideas in a semester.

\section{Nested Model}

Nested model is a design used by a competent teacher. This model in every subject, the teacher has targeted some of the competencies as social competence, thought competence, and special competence. By using nested model grouping some of the objectives in the learning experience, student learning quality becomes well off and improving. This model is properly used by the teacher for implanting thought of competence and cooperating competence to be their lesson.

\section{Sequenced Model}

This model is useful in the beginning stage of the integrated process; using two discipline science fields that are easily connected to each other. Teacher, work in pair, began with the content of the curriculum list separately. In this model, the two disciplines are still pure. Special emphasizing is still in the subject domain, but student gets to benefit from content related.

\section{E. Shared Model}

The shared model used when the material categorized in wide coverage as the humanities and practical art. This model is providing the beginning stage of application toward integrated curriculum. This model is a learning combination of appearing to intersect effect or idea in two subjects or more. By same discipline unit and intersect can provide a concept of learning deeper. Shared model based on together with ideas that are from science discipline.

\section{F. Webbed model}

Webbed model is an integrated approach for integration of lesson material. Commonly, integrated approach for developing a curriculum that started with a theme as "transportation" or "family". The conceptual theme provides diversity attributed to a kind of scientific discipline. When determining the theme, the teacher team begins in dialogue or discussion commonly.

\section{G. Treated Model}

This model focuses on meta-curricular that change the main concept of all subject content. Meta curricular approach relate the thought competence, social competence, plural intelligent, technology, and learning competence through a sort of scientific discipline. This model is properly used as an alternative step to integrated material learning intently.

\section{H. Integrated Model}

This model is an approach of cross-discipline that similar to a shared model. The integrated model combines four main discipline that determines curricular priority and determines intersect among competence, concept, and manner. Integrated is the result of idea extraction from subject content. In low level integrated model describe the important substances of holistic approaching and language competence.

\section{Immersed model}

This model designed to help the student to extract and combined sort of experience and knowledge connected with the user domain. Learning activity directed to contain the exchange of experience and each utilization of experience. Science discipline becomes a part of student observation, the student extracts all of the content through this observation and come in the experience themselves. In this model, integrated internally and intrinsically is reached by the student little or without pressure from outside.

\section{J. Networked Model}

In this model, the student directed the integrated process through individual selection from the network that needed. Only the student self-recognizes details and their field dimension so that they can search the resource that they needed. This model develops and motivates the student to the new direction. This model is a proper model to motivate the student. As a developing network, new invention encourages the student to the new depth and direct to more special creation.

\section{LEARNING MODEL APPLIED IN INDONESIA}

Ten model above, there is three model looked in qualification to develop and easy to implement informal education in elementary school [11]. Three models are connected model, webbed model, and integrated model.

Connected model is developing curriculum model that combines clearly a topic with the next topic, a concept with another concept, a competence with the other competence, a day activity with another day in a subject lesson. Example, learning uses type integrated learning connected is teacher connect or combine mathematic concept about money in purchase and sale concept, loss and profit, saving and loan, and interest. This model has applied to the learning of highlevel class of elementary school in Indonesia.

Webbed model is an integrated learning model using a theme as a basic learning. This Learning model combines multi-science discipline or as a subject tied to a theme. A theme can be applied by teacher and student or between the teachers. After the theme agreed so it is continued to select the sub-themes by observing of its relation between the other 
subjects. Therefore, a theme has to have coverage of material and providing the provision to the student for studying the next learning. The use of integrated learning webbed model is the student and teacher determining the theme such as water, windmill, dam water, river water, commercial water from Government Company that joined in mathematics lesson, social, science, and language. Learning by using thematic approaching has applied in lower level class in Indonesia.

The integrated model is a developing curriculum model using cross main science approaching with competence material, concept, and manner intersects categories. Applying integrated learning is teacher selecting the concepts of competence and behavior value that taught in one semester from kind of subject, for example, mathematics, social, science, and language. The next is selected some of concept, competence, and behavior value that have a relationship and intersect between some of the subjects.

\section{VIII.CONCLUSION AND SUGGESTION}

\section{A. Conclusion}

Constructivism used as basic of innovative and interactive learning in elementary school. Learning plan designed in syllabus form and lesson plan that refers to the standard of content. A good syllabus has elements: the identity of the school, core competence, basic competence, theme, material, learning activities, assessment, time allotment, and learning resource. A good lesson plan has elements; school identity, subject identity, or theme/subtheme, class/semester, major material, time allotment, core competence, basic competence, achieving indicator competence, learning objective, learning material, method, learning media, learning resource, learning steps, and learning assessment.

Although it faces many challenges, teacher or education instructor has the expectation for developing innovative and interactive learning principle by observing intellectual growth, emotional, social, physical potential, artistic, and creative. Besides, to develop learning innovatively and interactively teacher or education instructor implement the procedure in analyzing basic competence and learning indicator, student analysis, and learning resource, and doing an assessment.

\section{B. Suggestion}

Professional teacher or education instructor expected to able to develop a learning that is meaningful to the student. Innovative and interactive learning and has meaning need a good lesson plan. So, teacher or education instructor expected before implementing learning activity can develop a good lesson plan and innovative and interactive that found in curriculum and implementation of thematic learning based on scientific approaching implemented integrated [10].

\section{REFERENCES}

[1] S. Suciati, T. Belawati, D. A. Padmo, and S. Handayani, "Difusi Inovasi Pendidikan," 2015.

[2] I. W. Dasna, "Desain dan Model Pembelajaran Inovatif dan Interaktif," 2015.

[3] D. Gasong, Belajar dan pembelajaran. Deepublish, 2018.

[4] R. I. Arends, Learning to teach (9th Editio). New York: The McGraw-Hill Companies, Inc, 2012.

[5] A. Revell and E. Wainwright, "What makes lectures 'unmissable"? Insights into teaching excellence and active learning," Journal of Geography in Higher Education, vol. 33, no. 2, pp. 209-223, 2009.

[6] H. Beetham and R. Sharpe, Rethinking pedagogy for a digital age: Designing for 21 st century learning. routledge, 2013.

[7] M. F. Mascolo, "Beyond student-centered and teacher-centered pedagogy: Teaching and learning as guided participation," Pedagogy and the Human Sciences, vol. 1, no. 1, pp. 3-27, 2009.

[8] P. Eggen and D. Kauchak, "Strategi dan Model Pembelajaran Mengajarkan Konten dan Keterampilan Belajar Edisi Keenam," Jakarta: PT. Indeks, 2012.

[9] Y. J. Moogan and S. Baron, "An analysis of student characteristics within the student decision making process," Journal of further and Higher Education, vol. 27, no. 3, pp. 271-287, 2003.

[10] R. J. Fogarty and B. M. Pete, How to integrate the curricula. Corwin Press, 2009.

[11] U. Saud and M. Johnston, "Cross-cultural influences on teacher education reform: reflections on implementing the integrated curriculum in Indonesia," Journal of Education for Teaching, vol. 32, no. 1, pp. 3-20, 2006. 